\title{
Market Efficiency and Technical Analysis Can they Coexist?
}

\author{
Ray R. Sturm, ${ }^{1, *}$ \\ ${ }^{1}$ Department of Finance, College of Business Administration, University of Central Florida, \\ 100 Weldon Blvd, Sanford, F1 32773, USA \\ *Correspondence: Tel: 1-407-708-2829. E-mail: rsturm@ucf.edu
}

Received: June 19, 2013 Accepted: July 16, 2013 Published: July 24, 2013

doi:10.5296/rae.v5i3.4049 URL: http://dx.doi.org/10.5296/rae.v5i3.4049

\begin{abstract}
Market efficiency is generally accepted in the academic community even though it cannot fully describe reality. Primarily due to noise, prices merely reflect beliefs about a firm's unknown true intrinsic value which makes behavioral finance important. Technical analysis attempts to measure changes in these beliefs to predict stock prices and should have value given the evidence in behavioral finance, the use in practice and the conditional predictability of human behavior. Moreover, the lack of academic evidence in technical studies probably results from the violation of two foundational principles in the discipline.
\end{abstract}

Keywords: technical analysis; behavioral finance 


\section{Introduction}

The hypothesis of market efficiency and the use of technical analysis are diametrically opposed in their implications, yet remarkably similar in their foundation. Both recognize that prices generally reflect all information about a stock, but one uses this recognition to argue that prices cannot be predicted while the other uses the same recognition to argue that prices reflect trends in investor sentiment that can be predicted. Clearly, both cannot be correct.

While technical analysis as a methodology may be as old as the markets themselves, the academic literature has been slow to embrace it. In the seminal paper, Fama (1965) convincingly argues that market price innovations should be identically and independently distributed and while price patterns will inevitably be found via data-mining, the patterns will not be predictable because they are spurious in nature. Similarly, Black (1971) admits that technical methods of analysis seem like they should work, but as traders anticipate the signals earlier and earlier, the signals become valueless. These papers, and others that followed, led the academic community to accept weak-form market efficiency over technical analysis.

In addition, the academic community has largely embraced market efficiency and mostly dismissed technical analysis because the evidence supporting market efficiency is plentiful while the evidence supporting technical analysis is sparse. But there are at least two major challenges to this conclusion. First, many major institutions allocate resources to technical analysis indicating that they must value the information. To do otherwise would be irrational. Second, a plethora of evidence has been compiled in the academic literature, specifically in the area of behavioral finance, advocating that markets are not perfectly efficient.

This paper revisits the debate and argues that technical analysis should be valuable as implied by industry practices and as supported by the literature on behavioral finance because of the uncertainty surrounding value. However, any success documented in studies of technical analytics does not necessarily contradict market efficiency. Rather, the successes in technical analysis simply reflect an additional assumption inherent in the foundational principles of technical analysis. The paper is organized as follows. Section II identifies the key issues, Section III discusses the evidence and Section IV provides discusses the studies. Section V provides concluding remarks.

\section{The Theories}

\subsection{Market Efficiency and Technical Analysis}

At first glance, the goal of technical analysis appears to be at odds with the implications of market efficiency (weak-form) as argued early by Fama (1970). In his early paper, he argues that the definition of an "efficient" market is a market in which prices always "fully reflect" available information. But the work of Pring (1991) (which has often been referenced in the academic literature(Note 1) also generally agrees that prices reflect all information currently available. The difference is that Pring (1991) further argues that part of the information set discounted into prices is the "trends" in optimism and pessimism of the investing public; 
implying that when news is introduced into the market, either not everyone is immediately in complete agreement with the news' ramifications, or they cannot immediately act on the information. In either case, while there may be an initial reaction to the news, there may also be a subsequent reaction in the same direction as more and more investors become convinced of the news. Thus, Pring's (1991) argument does not necessarily contradict market efficiency, it merely recognizes that the full reflection of information may not be immediate.

Even in Fama's (1970) early efficient market hypothesis, he goes on to identify some market conditions necessary for a market to be efficient, none of which describe reality as he points out. Specifically, the market conditions Fama (1970) identifies as necessary for efficiency include a market in which there are no transaction costs, all available information is costlessly available to all market participants, and [investors] agree on the implications of current information. In addition, other potential sources of market inefficiency could be offered such as liquidity trading and trading by nonprice-takers who do not execute all of their trades at the same time.

More generally, Grossman and Stiglitz (1980), Lo and MacKinlay (1999), Palepu, Healy and Bernard (2004) and others also point out that perfect market efficiency cannot describe market equilibrium in the real markets. If markets were perfectly efficient, then there would be no reward for analyzing the information, so nobody would try and the information would no longer be discounted into prices. Hence, there must be enough inefficiency in the market to reward those who seek it.

\subsection{Noise, Behavioral Finance and Technical Analysis}

Another overriding and confounding influence on market efficiency is that of noise in the markets. In his seminal paper, Black (1986) proposes a model of the financial markets in which investors are described as either information traders or noise traders depending upon their decision-making process. In his model, prices will fluctuate around value as information traders and noise traders compete in the marketplace. In particular, he argues that the farther away from value a stock travels, the more aggressive information traders will become thereby driving prices back towards value. Black's (1986) proposition is consistent with Pring (1991) who describes the economy expanding and contracting around an equilibrium point. In Pring's (1991) model, the greatest return opportunities occur as investors' recognize the economy turning back towards equilibrium particularly if the economy is volatile. The goal of technical analysis is to identify these turns.

Black (1986) recognizes that noise arrives in many forms including noise in earnings-based estimates of value. Hence and consistent with previous seminal work by Fama (1965), information traders never know whether they are trading on information, or on noise. In Fama's (1965) work, he also points out that in a world of uncertainty, intrinsic values are not certain, so there will always be a difference between intrinsic value and actual prices. Finally, Pring (1991) points out that the equilibrium around which the economy expands and contracts is never known to investors. Accordingly, noise is always present in prices and even if it is not present, then investors are not aware of its absence so it will soon return. 
These studies, and others, precipitated a vast line of research on noise trading which is largely an academic exercise because for a firm with an assumed infinite life and non-constant cash flows, (Note 2) intrinsic value is never known. Accordingly and consistent with Pring (1991), a firm's stock price does not reflect the firm's true worth, but what investors believe the firm is worth. Recall that intrinsic value is estimated:
(1) $\mathrm{V}_{0}=\sum_{\mathrm{t}=1}^{\mathrm{n}}\left(\begin{array}{c}\Phi_{\mathrm{t}} \\ ----------- \\ \left(1+\mathrm{i}_{\mathrm{t}}\right)^{\mathrm{t}}\end{array}\right)$

where $\Phi_{t}$ is the firm's expected cash flow at time $t$ and $i_{t}$ is the appropriate discount rate at time $t$. Because $t, \Phi_{t}$ and $i_{t}$ are never known, $V_{0}$ will increase and decrease as beliefs about the correct value of these three variables are adjusted. Hence, the real task of technical analysis and consistent with John Maynard Keynes' (Myers 2010) is not to forecast these three variables, but to forecast investors' forecast of the variables. Further, since intrinsic value is never known even by information traders, then in reality, all traders are noise traders which makes behavioral finance important.

Of course, as investors' forecasts of these variables change, $\mathrm{V}_{0}$ will also change. Pring (1991) notes that financial markets are determined by investors' expectations of the economy and those expectations are rarely stable. The economy, he argues, is always expanding or contracting resulting in financial markets that are always expanding or contracting. As it pertains to Equation (1), the more (less) frequent the changes in forecasts, the more (less) frequent the change in $\mathrm{V}_{0}$ and the greater (lesser) the amount of change in the forecast, the greater (lesser) the amount of change in $\mathrm{V}_{0}$. It follows, therefore, that the less certain investors are about the accuracy of the forecasts, the more frequent and/or the greater the stock price change. Thus, a market with a greater (lesser) degree of variability in prices is indicative of a market with a greater (lesser) degree of uncertainty about $\mathrm{V}_{0}$. In either case, the presence of noise provides the canvas upon which behavioral finance is painted.

So if all investors are really noise traders, then measuring investors' beliefs about value should be at least as important as estimating value itself. This notion is consistent with behavioral studies in finance and with John Maynard Keynes' belief that predicting other peoples' behavior is the real goal in stock market investing (Myers 2010). Behavioral

Finance is a broad topic that can be defined as the study of human behavior in the financial markets for the purpose of understanding investors' actions in the financial markets. Of course for wealth maximizers, the ultimate goal of studying Behavioral Finance is to forecast future behavior among traders and by extension, future prices. In the investment industry, technical analysts share the same goal.

In general, technical analysis is the search for recurring patterns in stock prices (Bodie, Kane and Marcus, 2002) and is based on the theory that human decision-making and actions are not only observable in the changes of the supply and demand equilibrium (i.e. the changes in 
price), but that these changes form distinct patterns that repeat and are therefore predictable. Indeed, Pring (1991) contends:

...prices move in trends which are determined by the changing attitudes of investors toward a variety of economic, monetary, political and psychological forces.

Pring's (1991) argument is consistent with the literature on momentum beginning with Jegadeesh and Titman (1993), but it is in contrast to Black (1971) who, as noted earlier, argues that technical analysis seems like it should work except for the now well-known anticipatory decision-process that traders would use to arbitrage away any such patterns as they learn from past patterns. Yet, even now, patterns do not always appear to be arbitraged away as evidenced by the literature on momentum, the Presidential Election Cycle(Note 3), and other lines of research. Moreover, embedded in Black's (1971) argument is that while patterns should not repeat in the long-term, they may repeat in the short-term before investors have learned the pattern. Thus, the more (less) obvious the pattern, the more (less) quickly it should disappear.

In his early paper from the financial literature, Black (1971) also notes that technical analysis ought to work because of crowd instinct. That is, when prices are going up (down), people will be attracted to (repelled from) the market thereby increasing (decreasing) the demand and driving prices up (down) even more. He also notes that when prices break through (or fail to break through) a resistance area, the fact that people believe that it's important will make something happen. (Note 4) Black's (1971) logic is also consistent with Jegadeesh and Titman (1993) and with a later seminal paper by Scharfstein and Stein (1990) in which they propose a model of herd behavior. They argue that herd behavior among money managers could partially explain stock market volatility as they mimic each other's trades in an effort to preserve their reputations as sensible decision makers. By extension, herd behavior among money managers could also partially explain the literature on both momentum and overreaction as managers ignore their private information while they follow the crowd.

Both arguments, Black's (1971) notion of crowd instinct and Scharfstein and Stein's (1990) model of herd behavior, provide support for Pring's (1991) motivation in his treatment on technical analysis:

Human nature remains more or less constant and tends to react to similar situations in consistent ways. By studying the nature of previous market turning points, it is possible to develop some characteristics that can help to identify major market tops and bottoms.

The implications of this statement are clear - human behavior is predictable, human behavior explains price movements, therefore future prices are predictable. It makes sense that Pring's (1991) argument is more descriptive of reality since market efficiency can't describe reality and since noise masks a firm's true value. Hence, because investor behavior is important and technical analysis attempts to measure investor behavior, technical analysis should be important. But for technical analysis to be valuable, investors' behavior must be predictable. So is it realistic to believe that investors' behavior is predictable? 


\subsection{Predicting Investor Behavior}

Determining the predictability of investor behavior begins with a broader examination of the predictability of human behavior. In an early paper but from outside the financial literature, Tversky and Kahneman (1974) describe three cognitive biases that result in judgmental errors which they call representativeness, availability and adjustment from an anchor. They conclude that not only do these heuristics lead to errors, but that those errors are systematic and predictable. A complete literature review on the predictability of human behavior is of course impractical because it would probably require a mostly complete literature review of the psychology and sociology disciplines. Moreover, if the answer was unambiguous, both disciplines would be closed. However, Gilovich, Keltner and Nisbett (2011) provide a particularly useful overview of predicting behavior from the discipline of Social Psychology.

More specifically, they provide an overview of the research on the relation between attitudes and behavior, noting that attitudes can often be surprisingly poor predictors of behavior. This could be a challenge to technical analysts who argue that there is a link between prices and attitudes through behavior. Some reasons given for this counter-intuitive result are that attitudes are sometimes inconsistent, such as when people may acknowledge a person as a great actor, but still dislike the person for their arrogance. Also, attitudes are sometimes based on secondhand information, such as people's attitude about a public figure whom they have never met personally. Neither reason presents a serious challenge to technical analysis because it is not likely that investors view the stock market as a bad investment while at the same time, investing in it. In addition, investors certainly have first-hand information about their gains and losses.

Also, Gilovich, Keltner and Nisbett (2011) note that attitudes can become more powerful predictors of behavior under certain circumstances. For example, behavior becomes more predictable when it is based on direct rather than indirect information, such as when people experience a crisis versus when they only read about the same crisis in the newspaper. In the markets, this certainly occurs when people actually experience losses (for example) as a result of market declines, rather than simply reading about a market decline in the news media.

In addition to direct information, attitude-behavior consistency is higher when both are at the same level of specificity, such as an individual woman's attitude about birth control in general versus her attitude about birth control pills, versus her attitude about using birth control pills, versus her attitude about using them within the next two years. Citing the work of Davidson and Jaccard (1979), Gilovich, Keltner and NIsbett (2011) report that the correlation between attitudes and behavior rise from about .10 with respect to their attitude about birth control in general, to about .58 with respect to their most specific attitude about using birth control pills within the next two years. Active investors affect supply and demand and experience changes in wealth, so they are clearly at the same level of specificity suggesting a strong link between investors' attitudes and their behavior.

Particularly relevant to technical analysis is the idea that conscious attitudes can be bypassed by automatic behavior. That is, rather than reflecting on our attitudes before undertaking a 
certain behavior, Gilovich, Keltner and Nisbett (2011) note that behavior is often more reflexive than reflective and that the situational context may elicit behavior automatically. For example, someone who unexpectedly encounters a snake in the grass is not likely to first analyze the snake to assess whether or not it is poisonous and a threat. Rather, they are more likely to immediately jump away even if the snake turns out to be completely harmless.

Also particularly relevant to technical analysis is the recognition that behavior can have a powerful influence over attitudes, such as forcing a child to attend church against their will. While they may resist the ideologies in earlier years, Gilovich, Keltner and Nisbett (2011) report that a remarkable number not only continue later in life, but eventually embrace the sentiments that they originally resisted. Similarly, Aarts, Verplanken and Van Knippenberg (1998) also conducted an interesting study on repeated behaviors and the decision-making process on modes of travel. They conclude that any type of repetitive behavior becomes more and more habitual thereby incorporating less and less reasoning and planning; which is to say, their behavior becomes more reflexive than reflective.

The financial literature on overreaction clearly implies automatic and/or reflexive behavior and the following of trading rules is clearly automatic and/or repetitive behavior. Hence, it makes sense that to the extent investors' behavior is automatic, it should be measurable via technical analysis and then predictable. Moreover, intuition suggests that the more frequently investors trade, the more automatic their behavior is likely to be. Since more frequent trading is more likely for short-term traders, it makes sense that attitudes and behavior are more closely linked in the short-term as investors trade more reflexively or automatically.

However, Myers (2010) points out that behavior and attitudes often differ because both are subject to many other influences that complicate the relationship. He argues that predicting behavior from attitudes can be illustrated by predicting a baseball player's results at bat based on the baseball player's skill. Predicting a skilled baseball player's outcome at any particular turn at bat is highly unreliable because of factors such as the weather, the pitcher, the type of pitch thrown, etc. However, these confounding influences can be neutralized through the principle of aggregation. That is, while any individual turn at bat (i.e. behavior) may result in large forecast errors, averaging the batter's total turns at bat should minimize the confounding effects and reveal the batter's true skill (i.e. attitude).

Similarly, predicting whether or not a person attends church (i.e. their behavior) on any given Sunday may be problematic due to factors such as the weather, work and vacation schedules, illnesses, etc. However, when aggregated, their average attendance over a longer time interval will probably be highly correlated with their religious convictions (i.e. their attitudes). Complicating relationships clearly applies to individual investors as their individual trading behavior may vary due to vacations, illness, mistakes, etc. However in aggregate, these complications should be offset by other investors although complicating information may remain. For example, if prices approaching a prior low normally triggers buying behavior, a terrorist attack may inject fear into investors thereby changing their behavior.

In sum, the extent to which human behavior is predictable remains an open topic for debate. However, there does appear to be supportive evidence from Social Psychology suggesting 
that at least partially predictable investor behavior is a reasonable expectation - especially because investors have direct information about their gains and losses, that information is at the same level of specificity, and investors' decision-making process is likely to result in repetitive or automatic behavior. So if market efficiency cannot describe reality, if noise masks value thereby making investor behavior important, if technical analysis measures investor behavior and investor behavior is at least partially predictable, then where is the evidence that technical analysis is valuable?

\section{The Evidence}

\subsection{Technical Analysis in Practice}

Even though the academic literature has only recently begun to embrace studies on technical analysis, there is compelling evidence that in practice, the information provided by technical analysis (i.e. past prices) is valued. For example, Kavajecz and Odders-White (2004) report that virtually all investment banks and trading firms employ technical analysts in their trading decisions. The fact that these institutions are willing to allocate resources to the methodology is evidence that they value the resulting information. Moreover, Park and Irwin (2007) cite Billingsley and Chance (1996) who found that about $60 \%$ of commodity trading advisors and $30 \%-40 \%$ of foreign exchange currency traders use technical analysis as a major or exclusive informational source in their decision-making process.

In addition to institutional research departments dedicated to technical analysis, stock exchanges also impose trading rules based on past price information alone, rather than firmor market-value based information. For example, the New York Stock Exchange (NYSE) imposes so-called circuit breakers to halt trading activity under extreme market volatility. From the exchange's website, the purpose of the circuit breakers is as follows:

In response to the market breaks in October 1987 and October 1989 the New York Stock Exchange instituted circuit breakers to reduce volatility and promote investor confidence. By implementing a pause in trading, investors are given time to assimilate incoming information and the ability to make informed choices during periods of high market volatility.

The most recent Rule 80B effective April 15, 1998 calls for trading halts at the $10 \%, 20 \%$ and $30 \%$ levels. The basic rules are that if the Dow Jones Industrial Average (DJIA) drops below $10 \%$ from the previous close before $2 \mathrm{pm}$ Eastern Time, the exchange imposes a one-hour halt in trading. If the DJIA drops below $20 \%$ before $1 \mathrm{pm}$, they impose a two-hour halt in trading, and if the DJIA drops below 30\% at any time during the day, the market closes for the day. Note that the rule is based on measures of past price changes, not on measures of intrinsic, market, liquidity, or other measures of value. (Note 5) The intent of the rule is clear - to curb panic selling. Equally clear is the reality that the trigger for panic selling is the comparison of current prices with past prices, not the comparison of current prices with estimates of current value.(Note 6) 
Besides exchanges, the SEC also imposed an uptick rule based on past prices alone for selling stock short. This rule, which the SEC is considering reinstating, allowed the short sale of a stock only if the previous trade resulted in a price increase. The intent was to mitigate short-sellers from adding to the momentum of a stock whose price has been declining. Finally, in addition to the commitment of resources to technical analysis by major institutions, and the exchange trading rules consistent with technical analysis, there are also a plethora of websites available that contain at least the basic tools of technical analysis. More importantly, technical analysis tools are available through brokerage accounts.

So in spite of the academic community's dismissal of technical analysis, technical analysis has been shown to be employed by institutions and the exchanges' rules on trading curbs and short-selling are based exclusively on past prices - a definition of technical analysis. Hence, rationality dictates that technical analysis must contain value. So why has the academy been unreceptive to technical analysis?

\subsection{Technical Analysis Undercover in the Academic Literature}

Campbell, Lo and MacKinley (1997) refer to technical analysis as "the black sheep of the academic finance community." Yet in the climate of academic skepticism, the discipline of technical analysis has not only survived, but thrived in the practicing community. However, upon closer examination, technical analysis has found its way into the mainstream academic literature as well, just under different names. Probably the best examples are in the literature on overreaction and momentum.

Technical analysis uses past price behavior alone to predict future price behavior, and both of these research lines are clearly consistent with this definition. For example, the seminal overreaction paper by DeBondt and Thaler (1985) forms portfolios based exclusively on past return information. They form winner and loser portfolios based on the stocks' prior 36-month returns, and find that winners tend to underperform and losers tend to outperform over the subsequent thirty-six months.

Likewise, the aforementioned seminal momentum paper by Jegadeesh and Titman (1993) also forms portfolios based exclusively on past returns. They find that returns over a shorter six-month period are related to previous six-month returns, but in their study, they find that winners tend to continue outperforming and losers continue to underperform. Both of these seminal studies spawned entire lines of research despite the fact that they are violations of weak-form market efficiency. Moreover, the support for the findings in both of these studies is not valuation per se, but human behavior that is also the foundation upon which technical analysis is built.

Many other studies could be cited as well, including Bremer and Sweeney (1991) who studied overreaction of daily returns, Jones and Winters (1999) who partially explain momentum returns as delayed reaction, George and Hwang's (2004) study of portfolios based on a stock's 52-week high, and others. The point is that while technical analysis has largely been openly shunned, it still appears to have found its way into the mainstream academic literature, just under other labels. 
More recently, a wave of papers more directly address technical analysis suggesting that the discipline is becoming more accepted in the academic literature. For example, Park and Irwin (2007) present an excellent review of the literature on technical analysis through 2004. They categorize the previous literature into early studies (1960-1987) and modern studies (1988-2004) and report that of the 95 modern studies on technical trading strategies, almost $59 \%$ of them (56 studies) found positive results, $20 \%$ found mixed results (19 studies) with only about $21 \%$ (20 studies) finding negative results. However, the stock market profits tended to disappear after the late 1980's, a result not surprising given the implementation of the modern computer.(Note 7)

So, in addition to evidence of the allocation of resources to technical analysis by institutions and the use of "technically based" trading rules imposed by exchanges, technical analysis has also been more widely accepted in the academic community than may be readily apparent. In addition, the theoretical foundation for technical analysis appears to be plausible as supported by Social Psychology, by the evidence that institutions and exchanges appear to value technical analysis and by major lines of academic research that have been created from studies using a technical approach. Together, it all implies that the lack of evidence from studies directly testing technical analysis could be the result of the testing methodology. So what criteria are necessary for technical analytics to reliably predict investor behavior and by extension, prices? The answer may lie in key underlying assertions by Black (1986) and Pring (1991).

\section{Necessary Criteria for Studies in Technical Analysis}

As noted earlier, Black (1986) conjectures that prices will fluctuate above and below intrinsic value as noise traders push prices away from intrinsic value and information traders drive prices back towards intrinsic value. Moreover, he points out that no trader can be assured profits, thus noise traders will face increasingly aggressive offsetting positions the further prices move away from intrinsic value. Based on this, technical analysis should be the most effective in highly emotional (i.e. highly noisy) markets. Therefore, one criteria for a plausible technical trading strategy that measures beliefs is that the more emotions there are in the market, the better, because the rule's effectiveness should be positively correlated with the market's noise.

Theoretically, noise or emotions could be measured as the difference between prices and intrinsic value and/or as the difference between the volatility of prices and intrinsic value. But in practice, such a measurement is impossible because as noted already, Fama (1965), Black (1986) and others show that the true intrinsic value is not known a priori and actual prices are just an estimate of intrinsic value that reflects all available information. Yet, informed traders should become increasingly (decreasingly) aggressive as prices move away from (towards) intrinsic value consistent with Black (1986). Therefore, volatility should be an indicator of the level of noise in the market.

For example, consider a market that has been trading at a consistent price (i.e. in a tight 
trading range) for an extended period of time. Such price behavior is indicative of a market that in aggregate agrees that the prices accurately reflect intrinsic value. By contrast, changing price-levels, particularly if they are changing rapidly, indicates disagreement in the market about intrinsic value. Accordingly, a plausible technical approach to investing comes from the argument that the success of technical analysis should be correlated with the volatility of returns - the higher the volatility, the more emotion there is to measure, thus technical analytics should be more valuable.

Another criteria necessary for a plausible technical trading strategy is that multiple indicators should be employed. Numerous studies in the academic literature examine the value of technical analysis, but as a whole, the results have been unconvincing. The reason may be that many studies violate a basic premise argued by Pring (1991), which is:

There is ...no substitute for independent thought. The action of the technical indicators illustrates the underlying characteristics of any market, and it is up to the analyst to put the pieces of the jigsaw puzzle together...

That is, no one tool by itself is always effective or successful, but several must be taken together in order to properly "read" the market's price changes. However, recent studies have begun to fill this gap. More specifically, the "combined signal approach" as employed in Savin, Weller and Zvingelis (2006), Loh (2007), Lento, Gradojevic and Wright (2007), Lento (2009) and others show that for a given set of indicators, using a combination of indictors is typically more valuable than using a single indicator in isolation. So the failure of evidence in the academic literature to find value in technical analysis may result from the violation of Pring's (1991) basic principle that no one indicator can expect to be correct all of the time. Accordingly, technical indicators should not be studied in isolation, but in combination.

While these two criteria are certainly not exhaustive, they do at least identify the climate and the methodology that will probably yield the best results for studying technical analysis. Assuming future studies yield more promising results, those results do not necessarily negate the hypothesis of market efficiency. Technical analysis assumes, as does market efficiency, that all information about an asset are reflected in the price of the asset. The difference is that technical analysis is based on the additional step that investors' aggregate beliefs about future prices, whether right or wrong, will lead them to act in predictable ways. Thus, while they may at first seem contradictory, market efficiency and technical analysis can coexist.

\section{Summary}

Whether or not markets are perfectly efficient has been a major debate in the academic literature throughout the markets' history. The academic community has largely accepted market efficiency over technical analysis because of the empirical evidence provided. This paper revisits the debate arguing that technical analysis should be valuable information for a number of reasons.

As pointed out in prior literature, market efficiency cannot describe reality since there must 
be enough inefficiency in the markets to reward those who seek it. That is, if nobody sought inefficiencies, then information would no longer be discounted into prices which would render markets less efficient. In addition, even the seminal literature on market efficiency acknowledges unrealistic assumptions regarding the necessary conditions for perfect market efficiency. Probably most importantly, another challenge to market efficiency is that of noise contained in fundamental and economic information that masks a firm's true intrinsic value. Because noise is ubiquitous, all investors are in reality noise traders.

Because of noise, stock prices do not reflect intrinsic value, instead they reflect beliefs about intrinsic value thereby making the discipline of behavioral finance important. Behavioral finance studies stock prices to infer investors' behavior and beliefs, and has provided academically accepted evidence that markets are not perfectly efficient. The most prevalent evidence is probably in the areas of overreaction and momentum. Since the discipline of technical analysis also seeks to infer investors' behavior and beliefs from stock prices, then by extension, technical analysis should be valuable.

Of course, even if beliefs and behavior can be measured, both behavioral finance and technical analysis assume that the behavior repeats in such a way that is predictable. Such an assumption appears plausible given the literature from the discipline of Social Psychology. More specifically, research from Social Psychology indicates that while not perfect, behavior can be predictable under certain circumstances such as when the behavior is automatic, reflexive or repetitive. All of these behaviors can be reasonably expected from traders, so it is reasonable to believe that traders' behavior is at least partially predictable.

Other evidence suggesting that technical analysis should be valuable comes from the practicing community. Many, if not most, large financial institutions employ technical analysis as one of their decision-making tools for investing. Additionally, the stock exchanges enforce rules based exclusively on past price information that are designed to mitigate panic selling in the markets - an acknowledgement of the effect of beliefs on prices. Because it would be irrational for so many institutions to allocate resources to technical analysis if it was not valuable, technical analysis should be valuable information.

Given that technical analysis measures beliefs, it follows that the most value would come from markets with the greatest difference in beliefs. As beliefs differ, price volatility should increase, so the value of technical analysis should be positively correlated with volatility. In other words, technically analysis is probably less valuable for low-volatility markets and more valuable for high-volatility markets. So one criteria for studies on technical analysis is that the markets studied should possess a reasonable amount of volatility. Finally, a foundational principle of technical analysis is that no one tool by itself is always effective or successful. Therefore, multiple tools should be employed to gain a more accurate measure of beliefs. For this reason, technical analysts have developed many tools to infer investor beliefs from prices.

Black (1971) argued so long ago, that technical analysis ought to work. Perhaps the lack of evidence on technical analysis in the academic literature thus far is the result of not distinguishing between high-volatility and low-volatility markets, as well as studying trading 
rules in isolation rather than in combination. Hence, a comprehensive theory of technical analysis is needed. Nevertheless, even if future studies discover value in technical analytics, such value does not necessarily contradict the hypothesis of market efficiency. Rather, it would lend validation to the additional assumption of technical analysis that attitudes of optimism and pessimism in the markets tend to trend; the result being that information may not be immediately discounted into prices.

\section{References}

Aarts, Henk, Bas Verplanken \& Ad Van Knippenberg. (1998). Predicting Behavior from Actions in the Past: Repeated Decision Making or A Matter of Habit? Journal of Applied Social Psychology, 28(15), 1355-1374. http://dx.doi.org/10.1111/j.1559-1816.1998.tb01681.x

Allvine, Fred C., \& Daniel E. O’Neill. (1980). Stock Market Returns and the Presidential Election Cycle: Implications for Market Efficiency. Financial Analysts Journal, 36(5), 49-56. http://dx.doi.org/10.2469/faj.v36.n5.49

Billingsley, Randall S., \& Don M. Chance. (1996). Benefits and Limitations of Diversification among Commodity Trading Advisors. Journal of Portfolio Management, 23(1), 65-80. http://dx.doi.org/10.3905/jpm.1996.409581

Black, Fischer. (1971). Implications of the Random Walk Hypothesis for Portfolio Management. Financial Analysts Journal, 27(2), 16-22. http://dx.doi.org/10.2469/faj.v27.n2.16

Black, Fisher. (1986). Noise. The Journal of Finance, XLI(3), 529-543. http://dx.doi.org/10.1111/j.1540-6261.1986.tb04513.x

Blume, Lawrence, David Easley \& Maureen O'Hara. (1994). Market Statistics and Technical Analysis: The Role of Volume. The Journal of Finance, XLIX(1), 153-181. http://dx.doi.org/10.1111/j.1540-6261.1994.tb04424.x

Bodie, Zvi, Alex Kane \& Alan J. Marcus. (2002). Investments(5 ${ }^{\text {th }}$ Edition). McGraw-Hill Higher Education.

Booth, James R., \& Lena Chua Booth. (2003). Is Presidential Cycle in Security Returns merely a reflection of Business Conditions?" Review of Financial Economics, 12(2), 131-159. http://dx.doi.org/10.1016/S1058-3300(02)00061-7

Bremer, Marc \& Richard J. Sweeney. (1991). The Reversal of Large Stock-Price Decreases. $\begin{array}{llll}\text { The Journal } & \text { 747-754. }\end{array}$ http://dx.doi.org/10.1111/j.1540-6261.1991.tb02684.x

Davidson, A. R., \& J. J. Jaccard. (1979). Variables that Moderate the Attitude-behavior Relation: Results of a Longitudinal Survey. Journal of Personality and Social Psychology, 37, 1364-1376. http://dx.doi.org/10.1037/0022-3514.37.8.1364 
DeBondt, Werner F. M., \& Richard Thaler. (1985). Does the Stock Market Overreact? The Journal of Finance, 40(3), 793-805. http://dx.doi.org/10.1111/j.1540-6261.1985.tb05004.x

Fama, Eugene F. (1965). The Behavior of Stock-Market Prices. The Journal of Business, 38(1), 34-105. http://dx.doi.org/10.1086/294743

Fama, Eugene F. (1970). Efficient Capital Markets: A Review of Theory and Empirical Work. The Journal of Finance, 25(2), 383-417. http://dx.doi.org/10.2307/2325486

George, Thomas J., \& Chuan-Yang Hwang. (2004). The 52-Week High and Momentum Investing. The Journal of Finance, 59(5), 2145-2176. http://dx.doi.org/10.1111/j.1540-6261.2004.00695.x

Gilovich, Thomas, Dacher Letner \& Richard E. Nisbett. (2011). Social Psychology, (2 ${ }^{\text {nd }}$ ed.) W. W. Norton \& Company.

Jegadeesh, Narasimhan \& Sheridan Titman. (1993). Returns to Buying Winners and Selling Losers: Implications for Stock Market Efficiency. The Journal of Finance, 48(1), 65-91. http://dx.doi.org/10.1111/j.1540-6261.1993.tb04702.x

Jones, Steven L., \& Drew B. Winters. (1999). Delayed Reaction in Stocks with Characteristics of Past Winners: Implications for Momentum, Value, and Institutional Following. Quarterly Journal of Business and Economics, 38(3), 21-40.

Kavajecz, Kenneth A., \& Elizabeth R. Odders-White. (2004). Technical Analysis and Liquidity Provision. The Review of Financial Studies, 17(4), 1043-1071. http://dx.doi.org/10.1093/rfs/hhg057

Lento, C., N. Gradojevic \& C. S. Wright. (2007). Investment Information Content in Bollinger Bands? Applied Financial Economics Letters, 3(4), 263-267. http://dx.doi.org/10.1080/17446540701206576

Lento, Camillo. (2009). Volume, Variance, and the Combined Signal Approach to Technical Analysis. Journal of Money, Investment and Banking, 7, 75-87.

Lo, Adrew W., \& A. Craig MacKinlay. (1999). A Non-Random Walk Down Wall Street. Princeton University Press.

Lo, Andrew W., Harry Mamaysky \& Jiang Wang. (2000). Foundations of Technical Analysis: Computational Algorithms, Statistical Inference, and Empirical Implementation. The Journal of Finance, 55(4), 1705-1765. http://dx.doi.org/10.1111/0022-1082.00265

Loh, Elaine Y. L. (2007). An Alternative Test for Weak Form Efficiency based on Technical Analysis. Applied Financial Economics, 17(12), 1003-1012. http://dx.doi.org/10.1080/09603100600749352

Myers, David G. (2010). Social Psychology. (10 ${ }^{\text {th }}$ ed.). McGraw-Hill.

Neftci, Salih N. (1991). Naïve Trading Rules in Financial Markets and Wiener-Kolmogorov Prediction Theory: A Study of "Technical Analysis." The Journal of Business, 64(4), 
549-571. http://dx.doi.org/10.1086/296551

Osler, C. L., \& P.H. Kevin Chang. (1995). Head and Shoulders: Not Just a Flaky Pattern. Federal Reserve Bank of New York Staff Reports.

Palepu, Krishna G. Paul M. Healy \& Victor L. Bernard. (2004). Business Analysis and Valuation. ( $3^{\text {rd }}$ ed.). Thomson South-Western.

Park, Cheol-Ho \& Scott H. Irwan. (2007). What Do We Know about the Profitability of Technical Analysis. Journal of Economic Surveys, 21(4), 786-826. http://dx.doi.org/10.1111/j.1467-6419.2007.00519.x

Pring, Martin J. (1991). Technical Analysis Explained. (3 ${ }^{\text {rd }}$ ed.). McGraw-Hill, Inc.

Savin, Gene, Paul Weller \& Janis Zvingelis. (2006). The Predictive Power of "Head-and-Shoulders" Price Patterns in the U.S. Stock Market. Journal of Financial Econometrics, 5(1), 1-23.

Scharfstein, David S., \& Jeremy C. Stein. (1990). Herd Behavior and Investment. The American Economic Review, 80(3), 465-479.

Sturm, Ray R. (2013). Economic Policy and the Presidential Election Cycle in Stock Returns. The Journal of Economics and Finance, 37(2), 200-215. http://dx.doi.org/10.1007/s12197-011-9179-6

Tversky, A., \& D. Kahneman. (1974). Judgment under Uncertainty: Heuristics and Biases. Science, 185, 1124-1131. http://dx.doi.org/10.1126/science.185.4157.1124

\section{Notes}

Note 1. See Neftci (1991), Blume, Easley and O'Hara (1994), Osler and Chang (1995), Lento (2009), and others.

Note 2 . If the cash flow were perfectly constant, the firm could be valued with a high degree of certainty.

Note 3. See Allvine and O’Neil (1980), Booth and Booth (2003), Sturm (2013) and others.

Note 4. This of course is known as a self-fulfilling prophecy.

Note 5. Also notice that the rules are imposed on price declines, but not price increases.

Note 6. Current value can only be estimated since the true value of a firm is only known when the firm is sold.

Note 7. Other good literature reviews on technical analysis include Lo, Mamaysky and Wang (2000), Kavajecz and Odders-White (2004), Loh (2007), and others. 


\section{Copyright Disclaimer}

Copyright reserved by the author(s).

This article is an open-access article distributed under the terms and conditions of the Creative Commons Attribution license (http://creativecommons.org/licenses/by/3.0/). 